\title{
The Impact of “No Impact Man”: Alternative Hedonism as Environmental Appeal
}

\author{
Jen Schneider \\ Colorado School of Mines \\ Glen Miller \\ University of North Texas
}

\begin{abstract}
As No Impact Man, writer Colin Beavan conducted a one-year experiment to determine whether he and his family could reduce their environmental impact to zero while living and working in Manhattan. This paper examines the No Impact Man experiment as a kind of "eco-stunt," an attempt to both garner significant media coverage and to disseminate an environmental message about how to live the "good life" without unduly damaging the natural world. We explore the potential of this kind of appeal, using Kate Soper's concept "alternative hedonism," and examine the strengths and limitations of alternative hedonism as it is enunciated through the ecostunt framework. We find that alternative hedonism constitutes a form of environmental appeal that could have potential with some audiences; however, its mass appeal is compromised by the limitations of the eco-stunt format.
\end{abstract}

Keywords: Alternative hedonism; eco-stunt; image event; No Impact Man

\section{Introduction}

This paper presents the development of “alternative hedonism,” a potentially significant trend among elites in the global North who are concerned about environmental degradation and who seek an alternative vision of the "good life" that is not based on an unexamined consumer identity or overwork. Specifically, the paper analyzes in depth one alternative hedonism-related "eco-stunt," which served to publicize and capitalize on this trend as environmental action: The "No Impact Man” experiment. Alternative hedonism, a concept developed by environmental philosopher Kate Soper, is an intriguing philosophical approach to living within and yet against environmental degradation and consumer culture (Soper et al., 2009). However, its value may be degraded by the eco-stunts - the broadly visible communicative acts - that sometimes publicize it. While there is significant potential in alternative hedonism to refocus environmental appeal toward environmentally beneficial versions of happiness and collective action, the eco-stunt necessarily must over-focus on individual action, media attention, and spectacle in order to break through media norms and gain coverage.

One of the more prominent of these recent eco-stunts, the No Impact Man experiment, may be seen in this way: as overly focused on individual media spectacle and not focused enough on collective action. Furthermore, No Impact Man's communicative acts can be intercepted by readers or viewers of his blog, book, and documentary at a variety of junctions, promoting a decontextualization of his experiment and its arguments from a larger and richer alternative hedonist framework. Although No Impact Man, the writer Colin Beavan, develops a sophisticated and thoughtful defense of his own experiment, it nonetheless remains problematic as a communicative "event." We also understand that more work-such as comparative explorations of other ecostunts-needs to be completed in order to fully explore the possibilities and limits of this particular trend.

At the same time, we find that Beavan's project can be seen as a possibly significant form of environmental address: the use of alternative hedonism appeals has the potential to reach certain audiences, particularly those with notable purchasing power, and shift the way humans conceive of their relationship to the natural 
This is an author-produced, peer-reviewed version of this article. The final, definitive version of this document can be found online at Environmental Communication, published by Taylor \& Francis. Copyright restrictions may apply. doi: $10.1080 / 17524032.2011 .611524$

world and consumption practices that degrade it. We aim, therefore, to both highlight the transformative philosophical potential of Beavan's alternative hedonism while at the same time reflecting on its limitations as a form of communication.

\section{Who Is No Impact Man?}

No Impact Man (NIM) is Colin Beavan, a free-lance writer located in Manhattan, New York. Before taking on the NIM experiment, Beavan was a writer of popular historical non-fiction books and, as he tells it, was looking for a new project to pitch to his agent (Beavan, 2009a, 10-12; Gabbert and Schein 2010). He also states that he was looking to become more of an "activist writer" and wanted to write about his relationship with environmentalism (Beavan, 2008b; Gabbert and Schein, 2007). Beavan's idea was to become "No Impact Man,” a regular-guy-turned-eco-superhero, primarily through the process of reducing his and his family's environmental impact to near-zero over the course of a year. The NIM experiment, undertaken by Beavan, his wife Michelle, and their two-year-old daughter Isabella, was chronicled by Beavan's blog (2006-present), a documentary film (2010), and a full-length non-fiction book (2009), all titled No Impact Man. The experiment also received extensive national and international press coveragemost notably a feature-length story in The New York Times called “The Year Without Toilet Paper” (Green, 2007; for other coverage see Gabbert and Schein 2010).

After the NIM experiment ended, Beavan formed a non-profit organization by the same name-the No Impact Project-whose aim was to enable others to reduce their own impact following the NIM model (Beavan, 2010). As of this writing, Beavan claims that there have been over three million unique visitors to his blog; the book has been translated into 15 languages and sold 50,000 copies in the U.S.; and the film has been screened at over 1,000 events (Beavan, 2010a). He also states that 15,000 people have participated in the No Impact Project, which was additionally publicized by the left-leaning political blog The Huffington Post (Beavan, 2010a). While we are unable to characterize how audiences received Beavan's messages in this paper, we do take the substantial media coverage and public engagement with Beavan's work to be evidence that a form of communication worthy of study is occurring here.

The NIM experiment itself had two parts, which we call the reduction of harm phase and the enhancement of good phase. During the reduction of harm phase, Beavan and his family aimed to reduce their environmental impact over the course of a year to near-zero. The family eliminated their production of trash, gave up carbon-producing transportation, avoided purchasing new items, ate local food only, and eventually turned the electricity and heat off in their Manhattan apartment. During the enhancement of good phase, Beavan increasingly committed himself to volunteerism, working with a number of environmental non-profits to offset any environmental damage incurred while the reduction of harm phase was ramping up (Beavan, 2007). Beavan also engaged in some community organizing of his own, which is explored in greater detail below.

The NIM experiment is an exemplar of a kind of eco-stunt that has emerged with increasing frequency over the last decade. We use the term eco-stunt because these projects are meant to both highlight the importance of environmental action on the part of individuals and also leverage media coverage to disseminate an environmental message widely. Frequently undertaken by activists and writers, these ecostunts emphasize commitment to environmental action that challenges status quo forms of consumption in particularly mediagenic ways. For example, the 2006 “Compact” featured ten friends joining together in an agreement not to purchase anything new for an entire year in order to "go beyond recycling in trying to counteract the negative global environmental and socioeconomic impacts of U.S. consumer culture, to resist global corporatism, and to support local businesses, farms, etc.” (Kesel, 2006). Compacters posted about their experiences on a blog and received local, national, and international media coverage (e.g., Dunn, 2006; Jones, 2006). That same year, a UK journalist working for the BBC decided he would be “Ethical Man.” Like Beavan, Ethical Man Justin Rowlatt and his family of five gave up their automobile, airplane travel, and other forms of consumption for a year (Rowlatt, 2006). Rowlatt also chronicled his experiences in blog form on the BBC website. Similar eco-stunts were filmed on the Oprah Winfrey show (Winfrey, 2008) and in the documentaries Garbage: The Revolution Starts at Home (2009) and Recipes for Disaster (2008) (see Meisner, 2009). Finally, a number of books have been published dealing with similar types of projects: Plenty: Eating Locally on the 100-Mile Diet (Smith \& Mackinnon, 2008), Animal, 
This is an author-produced, peer-reviewed version of this article. The final, definitive version of this document can be found online at Environmental Communication, published by Taylor \& Francis. Copyright restrictions may apply. doi: $10.1080 / 17524032.2011 .611524$

Vegetable, Miracle (Kingsolver, 2007), and Sleeping Naked Is Green (Farquharson, 2009), among others. Other phenomena include organized consumer consciousness days, such as Bike to Work Day, Buy Nothing Day, and Buy Local Day. NIM shares much in common with these experiments and activism, which focus on the "stunt" aspects of environmental living - commitment to an unusual set of consumption rules, most commonly - and a desire to spread an activist-oriented message to the public about the importance of individual and collective environmental action.

In this paper, we refer to NIM as either an experiment (Beavan's preferred term) or as an eco-stunt (ours). The information about the No Impact Man eco-stunt presented in this paper is taken primarily from the NIM weblog (blog), available at http://noimpactman.typepad.com/. All posts from the experiment are archived at the site, and do not appear to have been modified over time (one of us has received email versions of the blog postings since the experiment began, has compared a number of those email postings with the current archive, and has not detected any differences). That said, analyzing a blog presents a number of challenges, not limited to the unreliability or changeability of the source material. Because of the layered nature of the blog/website, data collection can be challenging - there are a seemingly infinite number of pages and links that could be considered data. For the purposes of this paper, we refer to posts Beavan made on a near-daily basis about the experiment, beginning in 2007 and continuing to the present day, paying special attention to posts that elucidate Beavan's philosophy as it relates to alternative hedonism. Although we did not perform a rigorous content analysis across all NIM artifacts, we did triangulate what appears on the blog with content from the book, lengthily titled No Impact Man: The Adventures of a Guilty Liberal Who Attempts to Save the Planet and the Discoveries He Makes about Himself and Our Way of Life in the Process (Beavan, 2009a), and content from the documentary No Impact Man (Gabbert \& Schein, 2010). We reference the three different artifacts at different points below, and refer to some press coverage of the experiment as well.

The scope of this paper is limited primarily to the American context, but we are aware that significant manifestations of alternative hedonism and "eco-stunts" exist elsewhere around the world; Kate Soper has begun the work of analyzing particular efforts in the UK and Europe, and more future work could examine this trend in other national contexts. Furthermore, expediency prevents us from performing an analysis of audience reception of the NIM experiment in this paper. We look at the popularity of the NIM media artifacts and the coverage of them in the mainstream press as evidence that there is substantial public interest in Beavan's approach. Future work would need to examine the extent of his actual "impact" and audience reception beyond what is examined here, and further place it in context, comparing it more indepth with other eco-stunts.

\section{No Impact Man as Alternative Hedonist: The Environmental Appeal of Pleasure}

For the purposes of this paper, we have chosen to describe Beavan's eco-stunts-his communicative acts and philosophical stance-as exemplary of an "alternative hedonist" philosophy. Environmental philosopher Kate Soper defines alternative hedonism as "premised on the idea that even if consumerism were indefinitely sustainable it would not enhance human happiness and well-being (not, at any rate, beyond a point that we in the rich world have already passed)" (Soper et al., 2009, 3). Soper argues that alternative hedonism is not just a move away from negative effects such as climate change and obesity, but also one toward a happier, fuller life that is not rooted in the vagaries of consumerism. In other words, alternative hedonism calls to those who wish to restrict or modify their consumption behaviors not only because of fear, guilt, or responsibility, but because doing so will also make their lives better. For the affluent drawn to alternative hedonism, "The pleasures of the consumerist lifestyle as a whole are troubled by an intuition of the other pleasures that it contains or destroys, especially those that would follow from a slower, less work-dominated pace of life" (Soper et al., 2009, 4). Elements of alternative hedonism can be found in similar concepts from across disciplines and in a variety of contexts (see Darnovsky, 2000; Hess, 2009; Leff, 1995; and Schor, 2010, to name a few). Most emphasize a call for the logic of consumer capitalism to be replaced by values located in environmental preservation and human dignity. It is possible to argue that alternative hedonism-oriented values, which go beyond "green" consumption and acquisition to meaningfully redefine the good life in line with environmentalist values, may constitute a significant trend if not a movement (Peters, 2004). 
This is an author-produced, peer-reviewed version of this article. The final, definitive version of this document can be found online at Environmental Communication, published by Taylor \& Francis. Copyright restrictions may apply. doi: $10.1080 / 17524032.2011 .611524$

We have chosen to use Soper’s term "alternative hedonism,” and not economist Juliet Schor’s "plenitude” or Science-Technology-Society scholar David Hess's "localism,” for example, because we believe it has significant communicative dimensions. We find the focus on pleasure as an element of environmental action to have potential as a form of environmental address with some audiences. Alternative hedonism has limitations - which we discuss at length later in the paper-but it may function as a compelling alternative to the forms of rhetorical address that typify many environmental appeals, particularly those having to do with global environmental crises such as climate change. These forms of rhetorical environmental address include the jeremiad (e.g., Opie and Elliot, 1996; Singer, 2010), melodrama (Schwarze, 2006; Kinsella, 2008) and, most commonly, tropes of apocalypse or disaster (e.g., Buell, 2003; Foust and Murphy, 2009; Killingsworth and Palmer, 1996; Russill, 2008). Although these appeals could be said to be effective for some audiences, the positive impact of sermonizing or emphasizing "gloom and doom" may be limited (see Moser and Dilling, 2007). Alternative hedonist appeals, on the other hand, focus on the pleasures, rather than fear or sacrifice, of environmental action. This emphasis on pleasure is frequently absent from studies of environmental appeal and therefore constitutes a valuable area for environmental communication scholars to study further.

When we have taught the concept of alternative hedonism to undergraduates, their most immediate critique is that alternative hedonism (particularly as embodied by NIM) is predicated on a certain amount of class privilege and social location. We think it is possible that alternative hedonist appeals may be most meaningful to or successful with privileged groups who have already-developed mainstream environmentalist sensibilities and the wherewithal and resources to act within the hedonist framework. As a result, we cannot argue that alternative hedonism is an appeal that will work for all audiences or groups, and it may even be theoretically problematic; by appealing primarily to the affluent, it is possible that alternative hedonism runs counter to collective values such as social justice (Darnovsky, 2000, 235). Future work should examine the potential and limitations of the alternative hedonist appeal for a variety of audiences given these constraints.

Although a complete critique of the functioning of privilege in alternative hedonism is beyond the scope of this paper, we should note that Soper acknowledges this limitation and nonetheless finds alternative hedonism an important subject of study (Soper et al., 2009, 4). While in most cases alternative hedonism is an exercise in privilege, it does capture a trend among a consumer class that out-consumes, on a per-capita basis, their less affluent counterparts. The actions of the affluent, particularly in the global North, can have real effects on global economic and environmental systems. For this reason, alternative hedonism may have significance for those who think about environmental communication trends.

For this reason, we find Soper's alternative hedonism to be an apt conceptual tool for understanding the primary appeal made in NIM. As this year-long experiment unfolded, made public by way of near-daily blog postings, Beavan's descriptions of himself and the motivations for the experiment notably shifted from being about the mechanics of the experiment (managing without toilet paper) and how to manage eco-grief, fear, or sacrifice, to being about the benefits of decreased consumption (the surprise at feeling happier with less). Beavan articulates the shift this way in his blog, posted half-way through the experiment: "So what if, as a society, we worried less about a booming economy which drains the planet of its resources? If, as the positive psychologists suggest, having more stuff isn't going to make us happier, shouldn't we worry more about things like building a culture that emphasizes personal connection and community?” (Beavan, 2007a; see also Beavan 2009b, 210). For Beavan, happiness, or the "good life," is predicated not simply on what can be purchased, but on the connections he makes with his family and community when he is not over-focused on consumption and work. The NIM experiment forced Beavan away from a focus on work and acquisition and toward those things that gave his life meaning: family, community, and environmental values. This may seem intuitive or mundane, but it forms the basis for Beavan's articulation of community activism. If we spend less time working and spending, he argues, we have more time to get to know our neighbors, our neighborhoods, the people who grow our food, and so on. These connections lead to deep feelings of satisfaction and happiness. And we also will be able to organize our communities more easily to protest environmental and social injustices as a result. 
This is an author-produced, peer-reviewed version of this article. The final, definitive version of this document can be found online at Environmental Communication, published by Taylor \& Francis. Copyright restrictions may apply. doi: $10.1080 / 17524032.2011 .611524$

We see a visual representation of these pleasures, personal benefits, and social connections in the NIM documentary. As the narrative of the experiment unfolds in the film, Beavan and his family appear to physically and mentally transform. At first, Beavan and his wife Michelle look wearied by the experiment: we see Michelle trudging up nine flights of stairs carrying canvas bags of groceries and two-year-old Isabella; Michelle struggles to give up caffeine and food "that tastes good;" Beavan grows despondent when the electricity is turned off and the apartment grows dark; even their complexions are sallow and tired. They are depicted as isolated, alone in front of their television and with their objects. However, as the experiment proceeds, the couple's skin begins to shine, they both lose weight, the apartment loses its clutter, and, as Michelle puts it, they "really start to get into the dividends" of the project. Beavan argues,

What if we called it 'The Year I Lost Twenty Pounds without Going to the Gym Once'? Or 'The Year We Didn’t Watch T.V. and Became Much Better Parents As a Result'? Or if we called it 'The Year We Ate Seasonally and It Ended Up Reversing My Wife's PreDiabetic Condition'? There are actual benefits to living environmentally (Gabbert and Schein, 2010).

We also see the Beavans increasingly surrounded by friends, playing charades by candlelight, meeting the people who grow their food, and getting to know community organizers and others in the neighborhood.

The cinematography and editing of the film reinforce this transformation. At the beginning of the documentary, filmmakers capture Michelle watching reality television. Her face is darkly lit and she is absent from the conversation going on around her. She later speaks to the camera about her "really intense relationship with retail" and how she would like to change her life so that she is healthier and less "addicted" to shopping, reality television, and an unhealthy diet. As the film progresses, the apartment is pictured flooded in natural light during the day or candlelight in the evening, a romanticized setting for their transformation. The couple interacts more intimately, washing clothing in the bathtub with their feet, or playing cards in the dark as a lyrical soundtrack plays over montages of their transformation across seasons. Although the filmmakers capture the couple's struggles with the NIM experiment-the failure of the "pot in the pot," or non-electric refrigerator, for example, or their disagreements over whether to have a second child - the pleasures and "dividends" of living environmentally are also explicitly stated and made visible in the couple's very interactions and appearance. These are carefully mediated, convincing representations of the benefits of an environmental lifestyle and represent an articulation of alternative hedonism in practice. In essence, Beavan is not only performing an eco-stunt that will garner him money and celebrity, but also seems to reflect, philosophically, on the relationship between consuming and working less (or consuming alternatively) and human well-being and happiness. It is through these mediated images that the argument for alternative hedonism as environmental practice is made most explicit. However, this form of representation is not without risk: we explore the disadvantages of alternative-hedonism-as-eco-stunt below.

\section{The Perils of the Eco-Stunt: Alternative Hedonism as Media Spectacle}

Although Beavan and his team emphasize the philosophical benefits of alternative hedonism, the mainstream press and, perhaps inadvertently, the documentary and the blog, focus extensively on the "stunt" aspects: giving up toilet paper, eating only locally-grown food, and living without electricity. When we have shown the documentary or assigned sections of the book, our students are always most interested in the "how" of the stunt-how the Beavans purchased food, how they kept themselves clean, how they got around Manhattan, and so on. The stunt is the thing, for our students and for most journalists covering NIM (see Gabbert and Schein, 2010, for a range of press and public reactions). In this section, we wish to explore the inherent conflicts experiments or stunts like NIM face when they are both trying to develop a counter-intuitive environmental philosophy (alternative hedonism) and garner mainstream media attention to disseminate that philosophy.

As a philosophical concept, the No Impact Man experiment can be seen as one of the latest in a long history of narratives that have shaped the way we think about the natural world, environmentalism, consumerism, and agency. One could look to early transcendentalist writings by Emerson and Thoreau; the early conservationist movement (see Milstein, 2009); the back-to-the-land movements of the 1960s and 1970s 
This is an author-produced, peer-reviewed version of this article. The final, definitive version of this document can be found online at Environmental Communication, published by Taylor \& Francis. Copyright restrictions may apply. doi: $10.1080 / 17524032.2011 .611524$

and beyond (e.g., Warshall \& Brand, 1998); arguments for "small" economics or de-growth (e.g., Schumacher, 1973/1989); and calls for “voluntary simplicity” or intentional downscaling (e.g., Elgin, 1998) as precedents of the alternative hedonism experiments we are seeing today. Darnovsky (2000) argues that forms of voluntary simplicity became one of the defining trends of the 1990s (219), and Cox (2006) notes the tremendous growth of interest in "green consumption” in the 80s and 90s (376-7).

What makes NIM a uniquely postmodern experiment, however, is the manner in which Beavan and his creative team have managed his experiment as a media spectacle. Thoreau and Emerson may have written about their experiments, but they did not also have a blog and a documentary made about their efforts, and our overwhelming and rapidly changing media landscape would have been incomprehensible then. From an environmental communication perspective, the spectacular elements of Beavan's project raise important questions about how eco-stunts function as media or image events. It is our impression, after studying the three NIM media artifacts (blog, book, and film), that Beavan is convincingly genuine and self-reflective about the perils of publicizing such an experiment. But tensions remain: although Beavan claims to be running the experiment for himself and his family so that he can "live a life in line with his values" (Gabbert and Schein, 2010), by making NIM so public, does he also run the risk of seeming opportunistic or overly-mediated and therefore less genuine or believable? Taken as a whole, the NIM philosophy is coherent and convincing, but we also know that audience members will intersect with these three NIM artifacts at various points; some may read a few blog entries, but never buy the book or the movie. Others may see the film but never look at the blog or book, and so on. Can an alternative hedonism philosophy be communicated in a media environment that fosters brief points of contact rather than sustained interest across media artifacts? Does NIM run the risk of being critiqued for hypocrisy, sermonizing, or shallowness? Are audiences likely to dismiss Beavan's general message about pleasure and "dividends" because of the seeming radicality of his experiment? Or are audience responses likely to devolve into a shallow version of "green" consumption? From our perspective, these questions represent the core problematics of the eco-stunt.

Although we are unable to definitively answer these questions in this paper, we hope to point in some general theoretical directions that suggest possible responses. As described above, we define Beavan's experiment, in part, as an eco-stunt, or series of media events orchestrated to communicate a particular environmental philosophy. We rely on Kevin DeLuca's work in Image Politics, in which he focuses on the role and meaning of “image events” for environmental groups and scholars of rhetoric. We've modified the term image event to eco-stunt for our purposes, in order to capture the idea that there is both an environmental message being communicated and a risky communicative move being made, a stunt or trick that attempts to get the audience's attention and invite them to look deeper but which also risks further alienating a cynical audience. Like the image events DeLuca examines, the NIM experiment should be understood as the coordinated production of constructed, self-referencing, and interconnected media artifacts or events. We discuss here the ways in which the NIM experiment functions similarly to DeLuca's image events and also the ways in which it is significantly different. This analysis sets the stage for understanding how NIM's alternative hedonism works as rhetorical appeal, and elucidates its successes and failures in this regard.

DeLuca argues that, though problematic in some ways, modern environmental organizers have become "sophisticated media artists," capable of staging media events that have successfully highlighted the severity of environmental crisis (DeLuca, 2006, 5). These image events are supposed to function as "mind bombs" that "reduc[e] a complex set of uses to symbols that break people's comfortable equilibrium, get them asking whether there are better ways to do things" (DeLuca quoting a Greenpeace campaigner, 2006, 3). Although we would argue that NIM does aim to "ask whether there are better ways to do things," it clearly also differs from the image events DeLuca analyzes, such as those carried out by the organizations Greenpeace and EarthFirst! For example, the scope, scale, and level of risk undertaken by Beavan's experiment differs markedly from those of Greenpeace or EarthFirst! activists staging image events. DeLuca details the level of bodily danger-harassment, maiming, death-these activists faced. They frequently situated themselves as intervenors, the only thing standing between "nature” (e.g., whales) and that which wishes to harm nature (e.g., whale hunters). Such image events were also meant to create brief, fragmented video or camera spots that could be easily disseminated through mass media outlets. 
This is an author-produced, peer-reviewed version of this article. The final, definitive version of this document can be found online at Environmental Communication, published by Taylor \& Francis. Copyright restrictions may apply. doi: $10.1080 / 17524032.2011 .611524$

Conversely, NIM is a rather safe and sustained examination of the alternative hedonist idea. Beyond its stunt aspects, it is also an experiment or meditation on living alternatively to mainstream consumer values, not a direct challenge to specific acts of environmental degradation that can be caught on video. Furthermore, Beavan runs his experiment largely as an individual- or family-centered event, not as a collective action representing a particular environmental organization or political platform. The gravity and intensity of the backlash against NIM — and there was quite a bit, detailed in-depth in the documentary - could be said to pale in comparison to that faced by Greenpeace or EarthFirst! protesters. As Beavan's friend, gardening mentor, and critic Mayer Vishner puts it in the NIM documentary, "Where did all this crap come from? American corporate capitalism did all of it. If anyone really thought that you were going to have an impact there, you wouldn't be getting the [corporate mass media] attention you're getting” (Gabbert and Schein, 2010). This exchange between Beavan and Vishner occurs in Vishner's apartment, which is in some disrepair and feels noticeably more cramped than the one Beavan shares with his family. Vishner, marked as an environmental activist by his hippie-esque slogan-bearing t-shirts ("Plant-A-Lot: 25 Years Greening New York City"), long pony-tailed hair, and anti-capitalist rhetoric, is presented as a visual and philosophical counterpoint to Beavan's hipster, clean-cut, conciliatory appearance and attitude. Mayer's appearance, location, and rhetoric represent challenges to the status quo that are not immediately visible in Beavan's story. Beavan is presented in the documentary, in many ways, as likable, mainstream, and safe, and Vishner's point is that Beavan's experiment does not, in fact, pose any danger to corporate capitalism.

Despite the differences between the image events DeLuca analyzes and Beavan's coordinated media events, however, DeLuca's framework illuminates important elements of the NIM experiment and how it functions as an eco-stunt. DeLuca argues that his analysis looks at how image events can "reconstitute the identity of the dominant culture by challenging and transforming mainstream society's key discourses and ideographs" (DeLuca, 2006, 16). We argue below that this is exactly what the NIM experiment aims to do: it aims to bring light to our dependence on forms of environmental degradation that we may normally take for granted and which are normally rendered invisible by corporate capitalism. It may, therefore, supply audiences with an "environmental imagination" that "propels them toward social analysis and political involvement” (Darnovsky, 220-3; see also Craig, 2010). NIM also suggests that living life differentlywith less work and less consumption-may make us happier. This is the alternative hedonism appeal at work. Whereas much individual environmental action has the effect of inducing guilt, avoidance, or sacrifice, Beavan's argument emphasizes the fruits of taking environmental action, or the pleasures of "living a life in line with one’s values" (Gabbert and Schein, 2010).

Furthermore, Beavan's experiment emphasizes the extent to which we are dramatically locked in to certain ways of living simply because the systems that have been established to support our economic and social existence encourage and support only particular kinds of behaviors. When Beavan attempts to "unplug" as much as he can, he finds that his ability to do so effectively and with ease is significantly hampered by the ways in which cities are organized and built, food is produced and distributed, electric power and heat are provided, and so on. The experiment makes visible the hidden ways in which our behaviors, which frequently harm the environment, are often already prescribed or dictated, how "the existing infrastructure of consumption...hides the social nature of consumption, camouflaging the corporate and governmental forces that have embedded unsustainability into the 'American way of life'” (Darnovsky, 2000, 229). The freedom to live in ways that does not harm the environment is made very difficult by the systems we have constructed: we are mostly free to choose if our choosing lies within the already-determined capitalist system of overwork and overconsumption.

But this intentional unveiling of problematic capitalist systems may also be seen as the experiment's principle weakness. It could be argued that Beavan over-interprets the meaning of his individual actions as meaningful on a large scale in order to maintain the integrity of his alternative hedonist argument. The lack of a radically aggressive image or icon—a drowning polar bear, a small boat attacking a large whaling vessel-combined with the unexpected turn of the alternative hedonism concept from sacrifice to happiness, open him up to a wide array of points of disagreement and critique: he is not radical enough; no real change can occur through individual action; he and his project are bourgeois, only made possible through Beavan's privileged status and location; he is annoyingly earnest; he is too cerebral; he just doesn't get the scope and scale of the problems and what is required to address them. Whereas the Greenpeace 
This is an author-produced, peer-reviewed version of this article. The final, definitive version of this document can be found online at Environmental Communication, published by Taylor \& Francis. Copyright restrictions may apply. doi: $10.1080 / 17524032.2011 .611524$

images could quickly and easily communicate a particular narrative-ecowarrior underdogs fight massive corporate operations destroying the environment-the message of the NIM experiment is much more diffuse. Are we to shop differently? Eat locally? Compost? Vote green? What about those who want to engage in these actions but can't? At the end of the day, will any of this be able to address our pressing environmental crises?

In the blog and book, Beavan offers lengthy, thoughtful answers to such questions, and the appeal of the documentary-which focuses in particular on Michelle's playful resistance to the experiment-defuses some of the more obvious criticisms or discomfort with Beavan's NIM persona and stunt-oriented approach. Nonetheless, the NIM experiment, like all eco-stunts, finds itself in a double-bind. NIM shares with DeLuca's environmental organizations the need to both obtain media coverage, which may require being "radical” or "extreme," and at the same time promote sympathy for environmental activisim without losing most of a mainstream audience's attention. This is the central limitation of the eco-stunt as form. On one end of a spectrum of eco-stunts is the Greenpeace "mind bomb," which is discrete and clear in tone and message, and which meets mass media norms for gaining coverage (Anderson, 1997, 114-134). Yet the mind-bomb model may be too simplistic and problematic in its framing of environmental action as nearly always violent or confrontational, and in assuming the "bomb" lands on audiences the way it was intended. The impact on audiences may vary dramatically as a result, either by turning off mainstream audiences or, conversely, making them see mainstream environmentalism as more acceptable (Cox, 2006, 277-279). On the other end of the eco-stunt spectrum is NIM. Beavan has elucidated a compelling and thoughtful philosophy around individual environmental action and anticipates how he will be perceived by diverse audiences. However, NIM may either turn off mainstream audiences because it seems elite or absurd, or invite critiques for not being radical enough. One must publicize an environmental message in order to make an impact, but in so publicizing risks criticism for seeking attention.

An example of this dynamic can be seen in journalist Elizabeth Kolbert's strong critique of the NIM experiment, published in The New Yorker. Kolbert is perhaps best known for her three-part series on the devastating impacts of climate change worldwide in that same magazine, later published as a book (Kolbert, 2007) and is a respected voice in environmental journalism. Kolbert puts forth a compelling argument against NIM, and her critique highlights the difficult double-bind the eco-stunt finds itself in. Kolbert writes,

There's something a tad disingenuous here. Beavan is, after all, a man whose environmental activism began over lunch with his agent. And it doesn't take a Ph.D. in electrical engineering to see through his claims to experimental rigor [...]. When No Impact Man shuts off the power at his apartment, you might think that his blog would have to go dark (and along with it his compulsive checking of his ratings on Technorati). But every day Beavan bikes to the Writers Room, on Broadway at Waverly Place, and plugs in his laptop. Meanwhile, Michelle scooters off to work at the offices of BusinessWeek, and Isabella spends the day at the (presumably electrified) apartment of a sitter (Kolbert, 2009).

Beavan's experiment claims to have "experimental rigor:” Kolbert's critique shows that such rigor is manufactured, and dependent on privilege or status (having a flexible schedule and work environment as a writer, being married to a wife who writes for a business magazine, being able to afford "electrified" daycare). She critiques the hypocrisy of the experiment's rules and highlights a common discomfort with the eco-stunt: that it may not do what it says it does. For Kolbert, the very fact that Beavan has made NIM available for public consumption marks it as less genuine: it is too mainstream and not environmental enough, pretending to be radical when it is mostly attention-seeking shallowness.

The heart of Kolbert's critique, however, has to do with the fact that NIM is focused primarily on individual, rather than collective, action: "He worries a great deal about the environmental consequences of Michelle's tampon use and the shrink-wrap around a block of cheese. But when it comes to his building's heating system, which is apparently so wasteful that people are opening windows in the middle of winter, he just throws up his hands” (Kolbert, 2009, 74). Kolbert goes on to call on Beavan to rally his neighbors in the apartment building, encouraging them to agitate "to install a more efficient heating 
This is an author-produced, peer-reviewed version of this article. The final, definitive version of this document can be found online at Environmental Communication, published by Taylor \& Francis. Copyright restrictions may apply. doi: $10.1080 / 17524032.2011 .611524$

system” (Kolbert, 2009, 74). She argues that the sequel to Beavan’s book could be called "Impact Man,” and should center not on himself and the minutia of his isolated experiment, but on the work of engaging his community to address - with the power of numbers — systematic environmental problem-solving. These critiques are reminiscent of Mayer Vishner's critiques of Beavan in the documentary, when he argues, "My hesitation about your work is that it enables people to fool themselves that all they have to do is change the lightbulb and recycle their plastic bag. As long as they feel that way, no politician will pick it [environmental politics] up” (Gabbert and Schein, 2010).

Kolbert's critique also echoes the work of author Derrick Jensen, who frequently argues against alternative hedonism-oriented enviropolitics. In a short Orion magazine piece entitled "Forget Shorter Showers: Why Personal Change Does Not Equal Political Change,” Jensen argues, "Consumer culture and the capitalist mindset have taught us to substitute acts of personal consumption (or enlightenment) for organized political resistance. An Inconvenient Truth helped raise consciousness about global warming. But did you notice that all of the solutions presented had to do with personal consumption?” (Jensen, 2009). Similar points are made by political scientist Timothy Luke (1993) and by communication scholars Darnosky and Noël Sturgeon, who argue that any "greening" of corporate capitalism must be rooted in visions of social justice and the collective (Darnovsky, 2000, 235; Sturgeon, 2009, 171-185). Darnovsky argues that critiques like Jensen's and Luke's are typical of scholars and environmentalists who are "decidedly unimpressed with everyday environmentalism" because of its focus on individual consumption, favoring instead systemic or collective political action (222). These critics see individual action as a poor substitute for organized political action or policy shifts. We may begin with consumption, in other words, but we cannot end there.

Indeed, eco-stunts and alternative hedonist media events risk precisely what Kolbert and Jensen warn against: a devolution into isolated forms of "green consumerism" that have more to do with which products to buy than with encouraging real systematic change that benefits the environment. Furthermore, as we noted above, even if a more complex message about environmental living or consuming is craftedas we believe is the case with NIM — it is not guaranteed that all audiences will absorb that message beyond moving to green consumerism, or may be turned off by the particulars of the stunt itself, or find the publicizing of the stunt self-aggrandizing and not worthy of further action.

\section{“A Realizable Outlet for Our Concerns”: Alternative Hedonism as Invitation}

At the same time, we wish to offer a slight counter-narrative here, which emerged out of our study of the NIM experiment in its entirety. It is beyond the scope of this paper to make claims for how individual audiences received the alternative hedonist messages in the NIM experiment, but we do wish to suggest that NIM does, in fact, focus on collective action, and that Beavan's call to pleasure, joy, and happiness may be appealing to some audiences who are otherwise frightened or turned off by the intensity of commitment required by Jensen's or even Kolbert's vision of environmental action. The sheer numbers of visitors to Beavan's site and the media interest his experiment generated give us pause when we think about whether the NIM stunt has potential as a form of environmental appeal. We suggest that, though not rigorous, as Kolbert argues, Beavan's experiment was, in fact, a substantive and meaningful form of environmental action and communication, which has the potential to develop into a basis for meaningful collective change.

We think that it is possible that, by focusing on pleasure rather than sacrifice or difficulty, Beavan may expand the range of possibilities available to audiences who otherwise resist environmental action. As Foust and Murphy put it in their critique of apocalyptic environmental appeals, “...rather than maintaining the tragic apocalyptic assumptions that global warming is fated by the cosmos, rhetors may [instead want to] frame narratives to promote human agency" $(2009,163)$. One way of promoting human agency could be to focus on the pleasures of taking environmental action. One of the San Francisco Compacters, Rachel Kesel, puts it this way:

[W]e did it [the Compact] because it brings us joy - try it w/ 10 friends and you will laugh for a year. It's a direct way for us to engage w/ the ecological issues that we care about, while also considering the network of factors that feed into ecological crises, such 
This is an author-produced, peer-reviewed version of this article. The final, definitive version of this document can be found online at Environmental Communication, published by Taylor \& Francis. Copyright restrictions may apply. doi: $10.1080 / 17524032.2011 .611524$

as labor, market, health, poverty, and local economy issues. Working on this challenge provided a realizable outlet for our concerns. Giving ourselves that space for action makes it more possible for us to act on other scales (Kesel, 2007).

Mark Meisner makes a similar argument about eco-stunt-centered films: “Aside from their entertainment value, what I like about [these films] is not only the humor and sincerity they evoke, but also their approach to social change. [...] [T] he films thus give viewers the chance for social learning to take place in a format that is not just unthreatening, but actually inviting” (Meisner, 2009).

Furthermore, we need not necessarily see personal politics as always divorced from collective politics. Soper's response to Kolbert's critique of NIM might be to argue that, while alternative hedonism is certainly reliant upon what Raymond Williams called a "structure of feeling," which is individual and rooted in felt experience rather than the intellect or politics, alternative hedonism nonetheless "requires encouragement and reinforcement from the side of government, and cannot be expected to flourish or expand without it" (Soper, 2008, 2): “Those wanting to go by bike will need their cycle tracks provided (and trains that help rather than hinder cycle travel).... Public support for new forms of 'policing' of consumption (and associated growth driven forms of productivity) can be enhanced if government also provides for the 'alternative hedonist' experience” (Soper, 2008, 2). Alternative hedonism both encourages large-scale change, through political activism, and is best realized when supported by that large-scale systemic change. The one may provide an invitation to the other.

We would also like to suggest that, although we sympathize with Kolbert's portrayal of NIM, we find it somewhat inaccurate. While Kolbert portrays Beavan as a self-involved navel-gazer, we found him instead to be well aware of the need for large, collective action. More than once he rallies his blog readers to act collectively on an issue of public and environmental interest, mirroring almost exactly Kolbert's suggestion that he organize his neighbors. For example, through provocative blog posts, Beavan mobilizes NIM blog readers living in New York to push for safer bike lanes and laws in Manhattan. Beavan, a frequent bicyclist, wrote on his blog about almost being hit on his bike by a New York State senator, Jeff Klein, who was driving an automobile. Beavan posted the detailed letter he sent to Klein on the blog and then called on NIM blog readers to inundate the Senator's office with phone calls, letters, and media coverage of the incident, which they did (Beavan, 2008a).

Beavan then parlayed this pressure into a meeting with Senator Klein to discuss the importance of bike safety laws (with the help of a local non-profit organization). According to Beavan, the Senator was amenable to a number of proposals that would ensure increased bike safety, an outcome that would benefit many more people than just NIM (Beavan, 2008a). Beavan may not have rallied his apartment neighbors about their inefficient heating system, but he did do collective organizing in this case in order to effect change that improved not only his life as a biker on Manhattan streets but potentially the lives of others with similar environmentally-beneficial interests. The conclusion to the NIM documentary ends on a similar note, as we see Beavan volunteering for a number of environmental and social justice organizations, and delivering talks on his experiment to students and others. Finally, he began the non-profit No Impact Project, a form of collective organizing and consciousness-raising which has recruited a notinconsequential number of participants.

In fact, over the course of the NIM experiment, Beavan moves from simply blogging about his own experiences during the NIM year to meta-reflection on how what he has learned could be used as a rhetorical strategy for environmental communication and activism. He emphasizes that he focuses on pleasure because he found happiness and fulfillment as a result of NIM, but also because it is an effective strategy for communicating about environmental action: "This is important because we so often associate environmentalism with deprivation, which is a hard sell. But if we can find smart methods to associate abundant happiness or quality of life with environmentalism, then we're in a win/win situation" (Beavan, 2008c). This approach resonates with Darnovsky's defense of “everyday environmentalism” and sustainable consumption practices: "Though the politics of the emerging sustainable consumption movement are still in flux, it could well serve to push everyday environmentalism out of the household and supermarket and into arenas of activism and political engagement” (221; see also Killingsworth and Palmer, 1996a, 221). We believe this is one of the aims, and outcomes, of the NIM experiment. 
This is an author-produced, peer-reviewed version of this article. The final, definitive version of this document can be found online at Environmental Communication, published by Taylor \& Francis. Copyright restrictions may apply. doi: $10.1080 / 17524032.2011 .611524$

\section{Conclusion}

Kolbert's critique of Beavan, therefore, can be seen as consonant with a body of scholarly arguments in environmental and political communication that are wary of eco-stunts that emphasize individual actionparticularly the kind that encourages one to shop one's way to "green"-rather than collective action. The scope of many environmental crises is so broad and deep, it is difficult to imagine anything short of widespread cultural and political change addressing them. At the same time, if one examines Beavan's "experiment" in full, as it is described across his blog, book, and documentary, it becomes clear that Kolbert's criticism of Beavan is not wholly accurate. From the outset, Beavan's experiment included a shift from individual behavior change to engagement with organizations involved in collective environmental change. At one point, near the experiment's end, he uses the communicative power of his blog to mobilize change in favor of improved bicycle-protection laws in Manhattan. Whether he developed this valuing of collective action in order to ward off potential critique or because he valued it as the key mode of environmental change is not totally clear, but it is present in the design of his experiment and his own philosophy as it unfolds across the NIM media artifacts.

Yet it is exactly the fact that Kolbert misses-intentionally or otherwise-these important facets of Beavan's experiment that should give us pause about the eco-stunt's potential to motivate collective rather than individual action. The majority of mass media coverage of Beavan's project focused primarily on the eco-stunt aspects of his project. Were one to engage with the project at any one point, whether the blog, book, or documentary, it is clear that what emerges as the strongest message is the emphasis on how he made his stunt work. It is unreasonable to expect that consumers of Beavan's message-whether a blog reader, a viewer of the documentary, or Kolbert-will hold him- or herself responsible for grasping Beavan's alternative hedonist philosophy across multiple media artifacts. Furthermore, audiences bring preformed conceptions about environmentalism and ecology to any eco-stunt. The irony is that Kolbert accuses Beavan of being overly concerned with his own media message, when in fact he may not have been concerned enough.

It is clear that there are tensions inherent in any ecostunt-or eco-experiment-such as Beavan's No Impact Man. Some of these projects seem troubling, too easy, too dangerously close to greenwashing or media manipulation. Part of our work, as scholars of environmental communication, is to try to better understand what is working in messages about the environment, and what doesn't work, and for whom. We should be careful to not too quickly or cynically dismiss environmental appeals simply because they are paired with carefully orchestrated "franchises" such as Beavan's. There is something meaningful and sincere in the alternative hedonist appeal, a call to reintegrate ourselves as consumers with our roles as citizens, parents, community members, partners, communicators, and so on. We may also need to advocate for those forms of communication that support heightened awareness and understanding of humanity's relationship to, and dependence upon, the natural world. We have tried to approach Colin Beavan's project in this spirit, to see it in part as eco-stunt, but also to understand how alternative consumption projects might provide a model for speaking and talking about the environment through the lens of human happiness and well-being. As Soper puts it: “...those in the academy who would wish to see it [alternative hedonism] develop into a more explicit and challenging form of opposition have a responsibility to engage with its tensions, reflect upon its ethical and aesthetic implications, and provide more explicit cultural representation of the non-puritanical but at the same time anti-consumerist 'political imaginary' to which it is gesturing” (Soper et al., 2009, 7). 
This is an author-produced, peer-reviewed version of this article. The final, definitive version of this document can be found online at Environmental Communication, published by Taylor \& Francis. Copyright restrictions may apply. doi: $10.1080 / 17524032.2011 .611524$

\section{References}

Anderson, A. (1997). Media, Culture and the Environment. New Brunswick: Rutgers University Press. Beavan, C. (2007). The Year-Long Plan. No Impact Man (weblog). Retrieved August 31, 2009, from the World Wide Web: http://noimpactman.typepad.com/blog/2007/02/the_no_impact_p.html.

Beavan, C. (2007a). What No Impact feels like after ten months. No Impact Man (weblog). Retrieved August 21, 2009, from the World Wide Web: http://noimpactman.typepad.com/blog/2007/10/what-no-impact-.html\%20.

Beavan, C. (2008a). A great visit with NY State Senator Klein--thanks to you. No Impact Man (weblog). Retrieved August 31, 2009, from the World Wide Web: http://noimpactman.typepad.com/blog/2008/10/a-great-visit-w.html

Beavan, C. (2008b). An open letter to NY State Senator Jeff Klein, who yesterday called me a f---ing asshle after nearly hitting me with his Mercedes. No Impact Man (weblog). Retrieved August 31, 2009, from the World Wide Web: http://noimpactman.typepad.com/blog/2008/09/an-openletter.html

Beavan, C. (2008c). The Problem with Happiness. No Impact Man (weblog). Retrieved August 21, 2009, from the World Wide Web: http://noimpactman.typepad.com/blog/2008/10/the-problem-wit.html

Beavan, C. (2009). Get a Happier Life! No Impact Man (weblog). Retrieved August 21, 2009, from the World Wide Web: http://noimpactman.typepad.com/blog/2009/08/get-a-happier-life.html

Beavan, C. (2009a). No Impact Man: The Adventures of a Guilty Liberal Who Attempts to Save the Planet and the Discoveries He Makes about Himself and Our Way of Life in the Process. New York: Farrar, Strauss, and Giroux.

Beavan, C. (2010). No Impact Project. Retrieved July 12, 2010, from the World Wide Web: http://noimpactproject.org/.

Beavan, C. (2010a). Thoughts on Communicating on Climate: My Remarks at Climate Negotiations Communication Conference. No Impact Man (weblog). December 3. Retrieved December 9, 2010, from the World Wide Web: http://noimpactman.typepad.com/blog/2010/12/thoughts-oncommunicating-on-climate-my-remarks-at-climate-negotiations-communication-conference.html.

Buell, F. (2003). From Apocalypse to Way of Life: Environmental Crisis in the American Century. New York: Routledge.

Cox, R. (2006). Environmental Communication and the Public Sphere. Chapel Hill: University of North Carolina.

Craig, G. (2010). Everyday epiphanies: Environmental networks in Eco-Makeover Lifestyle Television. Environmental Communication: A Journal of Nature and Culture, 4.2, 172-189.

Darnovsky, M. (2000). Green Living in a Toxic World: The Pitfalls and Promises of Everyday Environmentalism. R. Hofrichter, ed. Reclaiming the Environmental Debate: The Politics of Health in a Toxic Culture. Cambridge: MIT Press.

DeLuca, K. M. (2006). Image Politics: The New Rhetoric of Environmental Activism. Mahwah, New Jersey: The Guilford Press.

Dunn, C. (2006). The Compact: Buy Nothing New for a Year (or Two). Treehugger. December 22. Retrieved December 9, 2010, from the World Wide Web. http://www.treehugger.com/files/2006/12/the_compact_buy.php.

Elgin, D. (1998). Voluntary Simplicity: Toward a Way of Life That Is Outwardly Simple, Inwardly Rich. New York: Quill (William Morrow).

Farquharson, V. (2009). Sleeping Naked Is Green: How an Eco-Cynic Unplugged Her Fridge, Sold Her Car, and Found Love in 366 Days. New York: Houghton Mifflin Harcourt.

Foust, C.R., \& W.O. Murphy. (2009) Revealing and Reframing Apocalyptic Tragedy in Global Warming Discourse. Environmental Communication: A Journal of Nature and Culture. 3.2, July 151-167.

Gabbert, L., \& Schein, J. (2010). No Impact Man (pp. 90 minutes). US: Oscilloscope Laboratories.

Green, P. (2007, March 22). The Year Without Toilet Paper. New York Times.

Hess, D.J. (2009). Localist Movements in a Global Economy: Sustainability, Justice, and Urban Development in the United States. Cambridge: The MIT Press.

Jensen, D. (2009, July/August). Forget Shorter Showers: Why Personal Change Does Not Equal Political Change. Orion. 
This is an author-produced, peer-reviewed version of this article. The final, definitive version of this document can be found online at Environmental Communication, published by Taylor \& Francis. Copyright restrictions may apply. doi: $10.1080 / 17524032.2011 .611524$

Jones, C. (2006). Out of the Retail Rat Race: Consumer Group Doesn’t Buy Notion that New Is Better. San Francisco Gate. February 13. Retrieved December 9, 2010, from the World Wide Web: http://articles.sfgate.com/2006-02-13/bay-area/17282830_1_consumerism-buy-bernal-heights.

Kesel, R. (2006). New Year's Resolution. The Compact (blog). Retrieved August 26, 2009, from the World Wide Web: http://sfcompact.blogspot.com/2006/01/new-years-resolution.html.

Kesel, R. (2007). Scales and Moralizing. The Compact (blog). Retrieved August 26, 2009, from the World Wide Web: http://sfcompact.blogspot.com/2007/10/scales-and-moralizing.html.

Kingsolver, B. (2007). Animal, Vegetable, Miracle: A Year of Food Life. New York: Harper Collins.

Killingsworth, J., and J.S. Palmer (1996). Millenial Ecology: The Apocalyptic Narrative from Silent Spring to Global Warming. Green Culture: Environmental Rhetoric in Contemporary America. Eds. C.G. Herndl and S.C. Brown. Madison: The University of Wisconsin Press.

Killingsworth, J., and J.S. Palmer (1996a). Liberal and Pragmatic Trends in the Discourse of Green Consumerism. The Symbolic Earth: Discourse and our Creation of the Environment. Eds. J.G. Cantrill and C.L. Oravec. Lexington: The University Press of Kentucky.

Kinsella, W.J. (Ed.). (2008). Narratives, rhetorical genres, and environmental conflict: Responses to Schwarze's "Environmental Melodrama" (Special section). Environmental Communication: A Journal of Nature and Culture, 2, 78-109.

Kolbert, E. (2007). Field Notes from a Catastrophe: Man, Nature, and Climate Change. New York: Bloomsbury.

Kolbert, E. (2009, August 31). Green Like Me: Living Without a Fridge, and Other Experiments in Environmentalism. The New Yorker, 70-74.

Leff, E. (1995). Green Production: Toward and Environmental Rationality. New York: The Guilford Press.

Luke, T.W., "Green Consumerism: Ecology and the Ruse of Recycling.” The Nature of Things: Language, Politics and the Environment. Eds. J. Bennett and W.

Chaloupka. Minneapolis: University of Minnesota Press, 1993. 154-172.

Meisner, M. (2009). Green Family Values on Film. Indications: Environmental Communication and Culture Blog. Retrieved August 20, 2009, from the World Wide Web: http://indications.wordpress.com/2009/08/17/green-family-values-on-film/.

Milstein, T. (2009). Environmental Communication Theories. Enyclopedia of Communication Theory, vol. 1. Eds. S.W. Littlejohn and K.A. Foss. Los Angeles: Sage, 344-349.

Moser, S.C., and L. Dilling, eds. (2007). Creating a Climate for Change: Communicating Climate Change and Facilitating Social Change. Cambridge: Cambridge University Press.

Opie, J. and N. Elliot. (1996). Tracking the Elusive Jeremiad: The Rhetorical Character of American Environmental Discourse. The Symbolic Earth: Discourse and Our Creation of the Environment. Eds. J.G. Cantrill and C.L. Oravec. Lexington: The University of Kentucky Press.

Peters, R.T. (2004). In Search of the Good Life: The Ethics of Globalization. New York: Continuum.

Rowlatt, J. (2006). I am the Ethical Man. Ethical Man (weblog). Retrieved August 31, 2009, from the World Wide Web: http://news.bbc.co.uk/2/hi/programmes/newsnight/ethical_man/default.stm

Russill, C. (2008). Tipping point forewarnings in climate change communication: Some implications of an emerging trend. Environmental Communication: A Journal of Nature and Culture, 2.2, 133-153.

Schor, J. (2010). Plenitude: The New Economics of True Wealth. New York: The Penguin Press.

Schumacher, E. F. (1973/1989). Small Is Beautiful: Economics As If People Mattered. New York: Harper Perennial.

Schwarze, S. (2006). Environmental melodrama. Quarterly Journal of Speech. 92, 236-261.

Singer, R. (2010). Neoliberal Style, the American Re-Generation, and Ecological Jeremiad in Thomas Friedman’s “Code Green.” Environmental Communication: A Journal of Nature and Culture, 4.2, 135-151.

Smith, A., \& Mackinnon, J. B. (2008). Plenty: Eating Locally on the 100-Mile Diet. New York: Three Rivers Press.

Soper, K. (2008). Living Well (Within Limits): Exploring the Relationship Between Growth and WellBeing, Sustainable Development Commission Meeting at the Department for Environment, Food and Rural Affairs. United Kingdom.

Soper, K., Ryle, M., \& Thomas, L. (Eds.). (2009). The Politics and Pleasures of Consuming Differently. Houndmills/New York: Palgrave Macmillan. 
This is an author-produced, peer-reviewed version of this article. The final, definitive version of this document can be found online at Environmental Communication, published by Taylor \& Francis. Copyright restrictions may apply. doi: 10.1080/17524032.2011.611524

Warshall, P., \& Brand, S. (Eds.). (1998). Original Whole Earth Catalog, Special 30th Anniversary Issue. Whole Earth.

Winfrey, O. (2008). Waste Not, Want Not, The Oprah Winfrey Show. United States: Harpo Studios. 